\title{
The Virtues of Thisness Presentism
}

\author{
David Ingram ${ }^{1}$
}

(C) The Author(s) 2016. This article is published with open access at Springerlink.com

\begin{abstract}
Presentists believe that only present things exist. But opponents insist this view has unacceptable implications: if only present things exist, we can't express singular propositions about the past, since the obvious propositional constituents don't exist, nor can we account for temporal passage, or the openness of the future. According to such opponents, and in spite of the apparent 'common sense' status of the view, presentism should be rejected on the basis of these unacceptable implications. In this paper, I present and defend a version of presentism ('Thisness Presentism') that avoids the unacceptable implications. The basic strategy I employ is familiar-I postulate presently existing entities to serve as surrogates (or 'proxies') for non-present entities_-but some of the details of my proposal are more novel, and their application to these problems is certainly novel. One overarching thesis of this paper is that Thisness Presentism is preferable to other versions of presentism since it solves important problems facing standard iterations of the view. And I assume that this is a good positive reason in favour of the underlying thisness ontology.
\end{abstract}

Keywords Time Presentism - Thisness - Singular propositions · Open future · Temporal passage

David Ingram

david.ingram@nottingham.ac.uk

1 Department of Philosophy, The University of Nottingham, Humanities Building, University

Park, Nottingham NG7 2RD, UK 
Presentism is the view that, necessarily, it's always the case that only present entities exist. ${ }^{1}$ In slogan form: "only present things exist." Typically, presentism is described as the intuitive or 'common sense' view of time (Markosian 2004: 48). ${ }^{2}$ And even some opponents, who ultimately reject presentism, accept that the 'guiding intuition is compelling' (Sider 2001: 11). But many insist that presentism has unacceptable implications: if only present things exist, we can't express singular propositions about the past, since the obvious propositional constituents don't exist (cf. Fitch 1994), nor can we account for temporal passage (i.e. that what's present changes) (cf. Leininger 2015), or the so-called 'asymmetry of fixity' (i.e. the open future and closed past) (cf. Diekemper 2005). According to such opponents, and in spite of the apparent 'common sense' status of the view, presentism should be rejected on the basis of these unacceptable implications.

In this paper, I present and defend a version of presentism that avoids the unacceptable implications. The basic strategy I employ is familiar-I postulate presently existing entities to serve as surrogates (or 'proxies') for non-present entities-but some of the details of my proposal are more novel, and their application to these problems is certainly novel. The plan for the paper is simple. To begin, I sketch my preferred version of presentism, 'Thisness Presentism' (Sect. 1). Then, I present the three problems facing presentism, mentioned above, and describe how Thisness Presentism solves each problem in turn (Sects. 2, 3). In doing so, I also develop the view in more detail and respond to some objections to Thisness Presentism, anticipated by Ned Markosian (2004).

One overarching thesis of this paper is that Thisness Presentism is preferable to other versions of presentism since it solves important problems facing standard iterations of the view. And I assume that this is a good positive reason in favour of the underlying thisness ontology. ${ }^{3}$ Paraphrasing David Lewis, I say: "Why believe in a plurality of thisnesses?-Because the hypothesis is serviceable, and that's a reason to think it's true" (cf. Lewis 1986: 3). In this paper, I argue that Thisness Presentism is serviceable insofar as it solves several problems for presentism; I think that this constitutes very good indirect support for the view.

\footnotetext{
1 This is adapted from Markosian's (2004: 47, fn. 1) characterisation of presentism. For more detail on how to define presentism, see Crisp (2004), Sider (2006), and Tallant (2014), inter alia. Presentism, so understood, is primarily a claim about what there is. There's more to presentism, as a theory of time, than the ontological claim articulated ("only present things exist"), but this characterisation suffices as part of the preliminaries.

2 See also, e.g., Putnam (1967: 240), Bigelow (1996: 35-36), McKinnon (2003: 305-307), and Zimmerman (2008: 221-223), inter alia. One notable dissenter is David Lewis, who states: 'In saying that there are no other times ... it goes against what we all believe. No man, unless it be at the moment of his execution, believes that he has no future; still less does anyone believe that he has no past' (Lewis 1986: 204). But, as Trenton Merricks correctly notes, this challenge has purchase only against the view that 'everything is instantaneous' and that's not presentism (Merricks 2007: 124, fn. 6). Lewis's reaction doesn't undermine the apparent intuitiveness of presentism when presentism is properly formulated. Typically, presentists insist that we can express true propositions about the non-present, i.e. it's true that certain entities have existed.

3 See e.g. Adams (1979), Rosenkrantz (1993: 72-139) and Lycan (1994: 95-99) for some independent arguments in favour of the existence of thisnesses. In this paper, I concentrate on the claim that a thisness ontology is beneficial for presentists.
} 


\section{A sketch of Thisness Presentism}

\subsection{Preliminaries}

According to Thisness Presentism, there are presently existing 'thisnesses' (or 'haecceities') of past and present entities. A 'thisness' is the property of being a particular entity (or, if you prefer, being identical with an entity). For a given X, X's thisness is the property being (identical with) $x$, e.g. Stephen Colbert's thisness is the property being Colbert, and so on (Adams 1979: 6).

It's worth noting, as part of these preliminary remarks, that Simon Keller (2004: 96-99) briefly discusses this kind of view, which he calls 'Haecceitist Presentism', as a solution to the 'truth-maker objection' to presentism (cf. Sider 2001: 35-42). Keller's Haecceitist Presentism is an important precursor to Thisness Presentism, but Keller's view is both underdeveloped and under-defended. My aim is to develop Thisness Presentism and show how this view solves other problems facing presentism. It's also worth noting that my account of the nature of thisnesses is inspired by Robert Adams's (1979, 1981, 1986) ontology of thisness. One contribution of this paper is to develop and defend a view that usefully builds on Adams's picture in a way acceptable to presentists. Recently, there's been renewed interest in an ontology of thisness (cf. Diekemper 2009, 2014, 2015). But no one has yet acknowledged the considerable work that such an ontology can do in defence of presentism.

\subsection{An ontology of thisness}

Thisnesses are properties of a sui generis kind; a thisness is a particular, primitive, purely non-qualitative property of an entity. Hence, the following is true of (e.g.) Colbert's thisness, the property being Colbert: it can only be instantiated by Colbert; it's a simple, unstructured property, which isn't reducible to any purely qualitative properties of Colbert (or relations to other entities); the property involves Colbert (in a sense), although it's not constituted by him (qua primitive property); and, Colbert's thisness is something like an 'individual essence' of Colbert (i.e. it's an essential property of Colbert that only Colbert could ever exemplify $)^{4}$ and it shares some typical hallmarks of other (essential) properties.

Thisnesses can exist uninstantiated. Consider an individual, Anna, who begins her life at time $\mathrm{t}$ and who exists until $\mathrm{t}_{100}$, when she ceases to exist. Anna's thisness, the property being Anna, comes into being with Anna at $\mathrm{t}$ and is uniquely instantiated by her until $\mathrm{t}_{100}$. But, when Anna ceases to exist, her thisness continues to exist uninstantiated. So, on this view, there are thisnesses of past and present entities, but no thisnesses of future entities (cf. Adams 1986). This view is prima

\footnotetext{
4 The definition of 'individual essence' I have in mind is due to Robert Adams (1981) and Alvin Plantinga (1974), inter alia. Let's suppose that $\mathrm{P}$ is an essential property of $\mathrm{x}$ if and only if, necessarily, if $x$ exists, then $x$ exemplifies $P$; $P$ is an individual essence of $x$ if and only if $P$ is (i) an essential property of $\mathrm{x}$ and, (ii) necessarily, for all individuals $\mathrm{y}, \mathrm{y}$ exemplifies $\mathrm{P}$ if and only if $\mathrm{y}$ is numerically identical to $\mathrm{x}$ (cf. Menzel 2015: \$4.1.2).
} 
facie acceptable to presentists, who accept "only present things exist," since it's part of the nature of a thisness that Anna doesn't need to continue existing in order for her thisness to continue existing. (And it's the presently existing thisnesses of past entities that function as the (present) surrogates for past entities.) The idea that thisnesses can exist uninstantiated isn't particularly novel (cf. Adams 1986; Keller 2004), but no one has yet offered an account of the relationship between an entity and its thisness that's acceptable to presentists. I develop such an account towards the end of this section (in Sect. 1.4).

One upshot of Thisness Presentism is that there are thisnesses of past entities but no thisnesses of future entities. Why think that this is so? What sort of argument can be given in support of this restriction? Robert Adams (1986) provides one such argument, which I rehearse and endorse in what remains of Sect. 1. The line of reasoning is a development of his (1981) argument that there are no thisnesses of non-actual entities. Next, in Sect. 1.3, I briefly outline Adams's argument against thisnesses of non-actual entities and then move on to the argument against thisnesses of future entities.

\subsection{Two arguments}

Actualism is the view that, necessarily, it's always the case that only actual entities exist. ${ }^{5}$ (Slogan: "only actual things exist.") Adams (1981) argues that actualism is inconsistent with the existence of thisnesses of non-actual entities and, since actualism is true, so we should reject the existence of such thisnesses. But why think actualism is inconsistent with the existence of thisnesses of non-actual entities? The basic idea is simple: a property, such as being (identical with) $x$, cannot exist if $\mathrm{x}$ has never existed (and if $x$ isn't actual, then $x$ has never existed). Adams (1981) makes the point similarly, as follows:

To be the property of being identical with a particular individual is to stand, primitively, in a unique relation with that individual. This relation between an individual and its thisness is the crux of the argument. It would be absurd to suppose that being the property of being identical with me could be a purely internal feature of my thisness, not implying any relation to me. The relation between an individual and its thisness is essential to both of them. My thisness is a property that I would have in every possible world in which I would exist - but equally, my thisness could not exist without being mine. It could not exist without being the thisness of Robert Merrihew Adams. So if there were a thisness of a non-actual individual, it would stand, primitively, in a relation to that individual. But according to actualism non-actual individuals cannot enter primitively into any relation. It seems to follow that according to actualism there cannot be a thisness of a non-actual individual. (1981: 11)

\footnotetext{
5 See e.g. Adams (1974, 1981), Plantinga (1974, 1976), and van Inwagen (1986), inter alia. For a survey, see Menzel (2015). I assume actualism, which strikes me as a plausible thesis in the metaphysics of modality, but I don't argue for it.
} 
According to Adams, the existence of (e.g.) x's thisness, $T$, implies a relation with $\mathrm{x}$ that couldn't obtain if $x$ is non-actual. Paraphrasing Adams, "T couldn't exist without being x's thisness" and "T couldn't exist without the actual existence of x." On one interpretation, it's metaphysically impossible for x's thisness to exist without $\mathrm{x}$. But this is too strong, as I make clear in what follows. On a more sensible interpretation, it's (metaphysically) impossible for x's thisness to exist without the initial existence of $\mathrm{x}$.

To defend the claim that x's thisness cannot exist without the initial existence of $\mathrm{x}$ (and, in doing so, support the view that x's thisness comes into being with $\mathrm{x}$ ), let's turn to Adams's (1986) argument against the thisnesses of future entities. Consider the following statement of the argument, from Adams:

I was born in 1937. Among the many metaphysically possible continuations of the actual history of the world up until, say, 1935, there are surely some in which I would never have existed. It is plausible to conclude that I could have failed to exist even given everything that existed in 1935, or that had existed before then, or that exists timelessly-and, conversely, that all of those things could have existed even if I had never existed. But, as I have argued, neither my thisness nor any singular propositions about me exists in any metaphysically possible world in which I never exist; they are not among the things that could have existed even if I had never existed. It follows that they are not among the things that existed in 1935, or before, or that exist timelessly. My thisness, and singular propositions about me, cannot have pre-existed me because if they had, it would have been possible for them to have existed even if I had never existed, and that is not possible. (1986: 316-7)

Let's suppose that $\mathrm{x}$ is a contingent existent. Prior to the existence of $\mathrm{x}$, it's metaphysically possible that $x$ fails to exist. So, we can suppose there's some world $\mathrm{w}$, according to which it's possible (at time $\mathrm{t}_{0}$ ) that $\mathrm{x}$ will exist at $\mathrm{t}_{1}$ and it's also possible $\left(a t t_{0}\right)$ that $x$ will not exist at $t_{1}$. According to Adams, the existence of $x$ 's thisness $\mathrm{T}$ implies a relation with $\mathrm{x}$ that couldn't obtain if $\mathrm{x}$ is non-actual (so, $\mathrm{T}$ couldn't exist without the actual existence of $\mathrm{x}$ ). But, at world $\mathrm{w}$ at time $\mathrm{t}_{0}$, it's indeterminate whether $\mathrm{x}$ will actually exist. Hence, $\mathrm{T}$ cannot exist at $\mathrm{w}$ prior to the existence of $x$ at $t_{1}$. (And, given the nature of thisnesses, $x$ cannot exist and fail to exemplify T.) So, $\mathrm{x}$ 's thisness $\mathrm{T}$ comes into being with $\mathrm{x}$.

I find Adams's argument persuasive. Even so, it employs a principle about the contingent existence of future entities that some may find controversial. The principle is as follows:

For any two entities, $\mathrm{x}$ and $\mathrm{y}$, and for any time $\mathrm{t}$, if $\mathrm{x}$ existed before $\mathrm{t}$ ( or if $\mathrm{x}$ exists timelessly), and y exists contingently and comes into existence at $t$, then it would be metaphysically possible for $\mathrm{x}$ to have existed even if $\mathrm{y}$ had never existed (Adams 1986: 317).

This principle strikes me as immediately plausible. It's natural to think there are a number of 'ways the world might be' and a number of ways the future of the world might unfold. Further, a rejection of this principle amounts to a rejection of the pretheoretic notion that the future is 'open' (in a sense). That is, if the existence of 
future entities isn't contingent, then what will be is 'closed' or 'fixed'. Indeed, Adams notes that his position 'rests on the intuition that the future ... is metaphysically open in a way that the present and the past are not' (1986: 318).

This sort of argument should be particularly attractive to presentists, since presentists typically endorse the thesis that the future is open. In fact, some view securing the 'openness' of the future as a central motivation for adopting presentism (cf. Diekemper 2005: 223; Cameron 2011: 77). Hence, rejecting the principle upon which the argument (against thisnesses of future entities) rests, and thus rejecting the contingent existence of future entities, conflicts with at least one advertised motivation for presentism.

According to Thisness Presentism, $\mathrm{x}$ 's thisness $\mathrm{T}$ comes into being with $\mathrm{x}, \mathrm{T}$ is uniquely instantiated by $\mathrm{x}$ throughout $\mathrm{x}$ 's existence, and $\mathrm{T}$ continues to exist (uninstantiated) once $\mathrm{x}$ has ceased to exist. So far, I've used arguments from Adams (1981, 1986) to support the idea that T comes into being with $\mathrm{x}$, but I've not said enough to motivate the idea that $\mathrm{T}$ continues to exist (uninstantiated). In fact, one might worry that Adams's line of argument against the existence of thisnesses of future entities might be used against thisnesses of past entities as well. ${ }^{6}$ In what remains of Sect. 1, I offer some further defence of the idea that a thisness continues to exist (uninstantiated) once its bearer has ceased to exist. In particular, I develop an account of the relationship between an entity and its thisness that's acceptable to presentists.

\subsection{Two kinds of ontological dependence}

Adams's (1986) argument against the existence of thisnesses of future entities is perfectly consistent with the existence of thisnesses of past entities. The argument against thisnesses of future entities is based on the fact that the nature of thisnesses (i.e. particular, primitive, purely non-qualitative properties of some entity) implies a relationship between thisness and entity. This relationship cannot obtain if the entity in question is a future entity (for the reasons adduced above). However, this relationship can obtain if the entity in question is a past entity because past entities have existed. But this requires saying something substantial about the relationship between thisness and entity, which is consistent with presentism ("only present objects exist"), and this development is no part of Adams's ontology of thisness.

\footnotetext{
6 Adams (1986: 319) disagrees: 'Perhaps an objector will offer me the mirror image of the argument that I find persuasive against thisnesses of future individuals. ... This argument does not persuade me, because I do not believe that the same things could, logically and metaphysically, have existed now no matter what had existed earlier. There is a temporal asymmetry in our modal intuitions here. It is very plausible to say that the existence and identity of anything that exists now cannot depend logically or metaphysically on anything occurring later, but much less plausible to say that it cannot depend on what occurred earlier. Indeed, theses making the identity of individuals depend logically or metaphysically on various facts about their origins or antecedents have great intuitive appeal to many of us. Hence, I have no strong objection to saying that the thisness of [a past entity] exists now without [the relevant past entity] existing now, but that if [the past entity] had not existed earlier, that would have been impossible.' Once again, I find Adams's argument persuasive.
} 
According to Thisness Presentism, x's thisness, T, depends on X's having existed; $\mathrm{T}$ couldn't exist, for instance, if $\mathrm{x}$ had never existed. The existence of Socrates's thisness (e.g.) implies a relation with Socrates that couldn't obtain if Socrates had never existed. Importantly, this isn't the claim that Socrates's thisness can't exist now if Socrates doesn't exist now. One way to capture the relation between thisness and entity is as follows: Socrates's thisness ontologically depends on Socrates insofar as Socrates's thisness couldn't exist without the initial existence of Socrates. However, this ontological dependence doesn't imply that Socrates's thisness must cease to exist once Socrates ceases to exist. The initial existence of an entity is sufficient for the existence of its thisness; the loss of the entity doesn't necessitate the loss of the thisness. But, since ontological dependence (standardly construed) is a relation, and a relation cannot hold unless its relata exist, the relationship of ontological dependence between an object and its thisness shouldn't be construed in the standard way. To resolve this worry, I say that Socrates's thisness ontologically depends on Socrates in a 'non-rigid' way (i.e. not the standard 'rigid' relation of ontological dependence).

Let's introduce a 'rigid' notion of dependence (i.e. the standard construal of asymmetric ontological dependence) to serve as a contrast case. Here's a putative definition, from Lowe (2010: $\$ 1)$ :

$\mathrm{x}$ rigidly ontologically depends on $\mathrm{y}=_{\mathrm{df}}$ (i) necessarily, $\mathrm{x}$ exists only if $\mathrm{y}$ exists; and, (ii) it's not the case that, necessarily, y exists only if $\mathrm{x}$ exists.

Consider a standard example, involving an individual, Colbert, and the set whose only member is Colbert, \{Colbert $\}$ : \{Colbert $\}$ rigidly ontologically depends on Colbert, since \{Colbert \} exists only if Colbert exists (and it's not the case that Colbert exists only if $\{$ Colbert $\}$ exists). ${ }^{7}$ This captures the idea that if some object, $\mathrm{x}$, rigidly depends on another, $\mathrm{y}$, for its existence, then $\mathrm{x}$ can't exist without $\mathrm{y}$. But, as noted, this isn't the sense in which a thisness ontologically depends on an entity (in the temporal, presentist-friendly case).

Diekemper (2015) introduces the idea that x's thisness, T, 'non-rigidly' ontologically depends on $\mathrm{x}$. The 'non-rigidity' of the dependence is to be understood as temporal (rather than modal). The basic idea is as follows. The existence of T ontologically depends on x's initial existence, but T doesn't continue to depend on $\mathrm{x}$; $\mathrm{T}$ merely has depended on $\mathrm{x}$ (2015: 65-66). So, $\mathrm{T}$ depends on the initial existence of $x$ (not the continuing existence of it). But T doesn't always nonrigidly depend on $x$; the relationship of dependence doesn't always hold. It can't hold, for instance, when x doesn't exist. But this is no problem given the proposed non-rigid ontological dependence. There's some time at which a thisness (T) ontologically depends on an entity $(\mathrm{x})$ : the initial existence of it $(\mathrm{x})$. With this in mind, here's a putative definition of asymmetric temporal non-rigid ontological dependence:

\footnotetext{
${ }^{7}$ It's true that if $\{$ Colbert $\}$ exists then Colbert must exist. But there's an asymmetric (rigid) dependence nonetheless. \{Colbert\} exists in virtue of Colbert, not vice versa. Sets depend on their members (cf. Fine 1994: 4-5).
} 
$\mathrm{x}$ non-rigidly ontologically depends on $\mathrm{y}={ }_{\mathrm{df}}$ (i) necessarily, $\mathrm{x}$ exists only if $\mathrm{y}$ has existed; and, (ii) it's not the case that, necessarily, y exists only if $\mathrm{x}$ has existed.

This captures the idea that if $\mathrm{x}$ non-rigidly depends on $\mathrm{y}$ for its existence, then $\mathrm{x}$ can't exist without the initial existence of $y$. This is the sense in which a thisness (T) ontologically depends on an entity (x). This kind of ontological dependence is perfectly acceptable to presentists.

In what remains, I will develop Thisness Presentism (and provide additional details) across a series of replies to the problems facing presentism, mentioned at the outset. First, I show that my view can resolve a problem about the existence of singular propositions about the past (Sect. 2), and, in doing so, address a separate issue about how presentists can account for the 'asymmetry of fixity' (cf. Sect. 2.3). Then, I explain how Thisness Presentism solves a distinct problem about how to account for temporal passage (Sect. 3).

\section{Presentism and propositions}

\subsection{The problem with singular propositions}

Socrates was a wise, snub-nosed philosopher. So, the sentence 'Socrates was wise' is true and expresses a (true) proposition, $<$ Socrates was wise $>{ }^{8}$. This proposition is a singular proposition; it's expressed by a sentence that uses a name ('Socrates') and it's directly about some entity, Socrates, i.e. the direct referent of the name used in the sentence. Many philosophers think there are singular propositions. ${ }^{9}$ Indeed, if $<$ Socrates was wise $>$ is true, then the proposition must exist to be true. ${ }^{10}$ Among the philosophers who accept the existence of singular propositions, many believe that propositions are structured entities, with constituents, and that the constituents of structured singular propositions determine what the proposition is about. So, e.g., $<$ Socrates was wise $>$, might be partly constituted by Socrates himself (or by a unique property of Socrates, etc.), and this would determine that the proposition is directly about Socrates. ${ }^{11}$

\footnotetext{
8 I follow the convention that ' $\langle p\rangle$ ' denotes 'the proposition that $p$ '.

9 See e.g., Plantinga (1979, 1983), Adams (1981, 1986), Kaplan (1989), Fitch (1994, 1996), Cartwright (1997), King (2007), and Merricks (2012, 2015), inter alia. All cited agree there are singular propositions, but disagree about the nature of such propositions. The position to be defended here is closest to Adams's view (cf. 1986).

10 Timothy Williamson (2002: 233) puts the point neatly: 'if the proposition did not exist, there would be nothing to be true'. The truth of a proposition strictly implies the existence of that proposition. This presupposes the general view, sometimes called 'serious actualism', that an object $x$ has a property $P$ in a world $w$ only if $x$ exists in $w$ (Plantinga 1979: 145).

11 See e.g., Adams (1981, 1986), Salmon (1986, 2007), Soames (1987), Braun (1993), Fitch (1994, 1996), King (2007, 2014), Speaks (2012), and Fitch and Nelson (2014)), inter alia. All cited agree that propositions are structured entities and so endorse a broadly 'neo-Russelian' view of singular propositions.
} 
Presentists face a problem concerning the existence of structured singular propositions about the past. Structured propositions are partly constituted by other entities and so depend for their existence upon the existence of their constituents. But, if past entities don't exist at all, as presentists insist, then what constitutes structured propositions about past entities? For instance, what constituent can be provided for (e.g.) $<$ Socrates was wise $>$ ? The obvious constituent is Socrates. But Socrates doesn't exist. So, what constitutes singular propositions about the past? Put another way, how do such propositions about the past exist at all, if the obvious propositional constituents don't exist?

There's a clear solution to this problem available for Thisness Presentism. First, consider the following putative definition of singular propositions from Adams (1986: 315): 'a singular proposition about an individual $\mathrm{x}$ is a proposition that involves or refers to $\mathrm{x}$ directly, perhaps by having $\mathrm{x}$ or the thisness of $\mathrm{x}$ as a constituent, and not merely by way of x's qualitative properties or relations to other individuals'. Here's the solution, which follows neatly from the definition. ${ }^{12}$ Structured singular propositions about the past are constituted by thisnesses of past entities and not constituted by the (non-existent) past entities themselves. So, e.g., $<$ Socrates was wise $>$ is constituted by Socrates's thisness, being Socrates, and not Socrates himself. This singular proposition is directly about Socrates in virtue of having his thisness (a unique property of Socrates) as a constituent. According to Thisness Presentism, all structured singular propositions about the past are constituted by presently existing thisnesses; $<\mathrm{p}>$ is a singular proposition about an entity, $\mathrm{x}$, if $<\mathrm{p}>$ has $\mathrm{x}$ 's thisness, $\mathrm{T}$, as a constituent.

In Ned Markosian's (2004) state of the art defence of presentism, he anticipates this sort of solution and rejects it. (Markosian argues there are several problems for this approach and shifts his attention to other strategies.) In what remains of Sect. 2, I engage with objections adapted from Markosian and defend the account presented above. ${ }^{13}$ In the course of my replies, I develop Thisness Presentism in more detail.

\subsection{Singular propositions about the future}

The first objection is that the solution fails to account for structured singular propositions about the future. There are no thisnesses of future entities, and so no thisnesses to constitute propositions about future entities. Markosian argues that this is an unacceptable implication of the view, since it generates an important asymmetry between the past and future - there are structured singular propositions about the past but none about the mere future). And, according to Markosian, 'any

\footnotetext{
12 It's worth noting that Adams's definition is accepted by Markosian (2004: 49, fn. 4), amongst others, and Markosian is no friend of the thisness approach to singular propositions presented in what follows. See also, e.g., Plantinga (1979: 111) and Adams (1981: 3-4) who suggest singular propositions about x are constituted by $\mathrm{x}$ 's 'individual essence' rather than $\mathrm{x}$.

13 I assume that singular propositions (about the past and present) exist. So, an ontology that's unable to account for them is deficient in one important respect. One option for presentists is to deny there are singular propositions about the past. But this option strikes me as worse (prima facie) than one that accounts for them (cf. Markosian 2004: 53-54). That being said, I'm not convinced there are singular propositions about the future, for reasons I discuss in Sect. 2.2.
} 
adequate Presentist solution to the problem should treat the past and future as perfectly analogous' (Markosian 2004: 55).

However, I see nothing prima facie objectionable about presentists endorsing a solution involving the kind of temporal asymmetry highlighted. Presumably, Markosian's desideratum - that presentists should treat past and future as 'perfectly analogous' - is based on the idea that presentists endorse an 'ontological symmetry' (i.e. past and future objects are the same, both don't exist). ${ }^{14}$ But this doesn't establish that presentists cannot countenance any temporal asymmetry (i.e. any intuitive difference between past and future) whatsoever. For instance, past objects have existed (have been present), and future objects haven't yet existed (haven't been present). Prima facie, presentists aren't compelled to reject this asymmetry, and Markosian gives no reason to think otherwise. At least, there's no reason to think this temporal asymmetry is ruled out by presentism's ontological symmetry. Furthermore, consider what Diekemper (2005) calls the 'asymmetry of fixity': the future is 'open' but the past isn't. ${ }^{15}$ Most presentists would likely endorse this temporal asymmetry. In fact, some motivate presentism by appeal to the idea that the future is open. ${ }^{16}$ Once again, it seems there's nothing that compels presentists to reject this general and intuitive difference between past and future. Indeed, if one motivates presentism by the idea that the future is open, then one must surely embrace this difference.

So, is there independent reason to think endorsing that 'there are no structured singular propositions about the (mere) future' is objectionable? This is a fair question. Here's one main reason to accept structured singular propositions about the past. It's natural to think $<$ Socrates was wise $>$ is the meaning expressed by the sentence 'Socrates was wise'. It's also reasonable to think the proposition, and not the sentence, is the fundamental truth-bearer (cf. Merricks 2015: 22-29). And if the proposition didn't exist, there would be nothing to be true. This seems a good reason to accept propositions about past entities, but it doesn't obviously extend to propositions about merely future entities. Although we might think $<$ My granddaughter will be tall $>$ is the meaning expressed by 'My granddaughter will be tall', nothing compels us to accept that my granddaughter will be tall is true. Since most presentists accept the future is open, presentists can sensibly remain undecided about whether there are true singular propositions about merely future entities. ${ }^{17}$

One might object that this argument proves too little, since presentists must accept the existence of some true propositions about the future. Certainly, the

\footnotetext{
14 I borrow the term 'ontological symmetry' from Diekemper (2005).

15 David Lewis describes this asymmetry as: "the obscure contrast we draw between the "open future" and the "fixed past"'. Lewis notes '[we] tend to regard the future as a multitude of alternative possibilities ... whereas we regard the past as a unique, settled, immutable actuality' (Lewis, 1979: 459). For Lewis and others, this captures a 'genuine and important' temporal asymmetry. I discuss this asymmetry and Diekemper's (2005) challenge that presentists can't account for it in Sect. 2.3.

${ }^{16}$ For instance, Ross Cameron notes that '[a] central motivation for adopting presentism is to secure the claim that the future is open' (Cameron 2011: 77). Indeed, it's also part of the motivation for thinking there are thisnesses of past entities (but no thisnesses of future entities) as discussed in Sect. 1.

17 See e.g., Bourne (2011).
} 
argument doesn't carry over to all propositions about the future, including many singular propositions about the future (e.g. $<$ The sun will rise tomorrow $>$, etc.). ${ }^{18}$ But this is perfectly consistent with Thisness Presentism, which has the resources to deal with all (true) structured singular propositions involving past and present entities, some of which may be directed towards the future. My concern here is with (true) structured singular propositions about merely future entities, i.e. things that haven't yet existed (haven't been present), since that's the focus of Markosian's first objection. I say there are no such propositions, nor could there be (cf. Sect. 1.3; Adams 1986) — but I don't say there are no propositions (singular or non-singular) about the future at all.

Even so, one might press the objection and insist that there are some (true) singular propositions about merely future entities. ${ }^{19}$ For instance, suppose that I plan to carve a statue from a lump of clay and that I name my future creation 'Goliath'. It seems I can believe and assert things about Goliath, e.g. 'Goliath will be ten-feet tall', even though I haven't yet carved the statue (and Goliath doesn't exist). So, there are (true) singular propositions about a merely future entity, e.g. $<$ Goliath will be ten-feet tall>, expressed by sentences that use the name 'Goliath'. (Or so the objection goes.) And, hence, Thisness Presentism is in trouble, since it cannot account for such propositions: there are no thisnesses of merely future entities, and so no singular propositions about such entities.

I think this objection fails for familiar reasons (i.e. those articulated in Sect. 1.3). Although it seems I can believe and assert things about Goliath (prior to carving the statue), there are no (true) singular propositions about Goliath prior to Goliath's existence. Following Adams (1986), there are no singular propositions about entities that never exist, so there cannot be singular propositions about entities that haven't yet existed. Paraphrasing Adams, "Goliath's thisness, and singular propositions about Goliath, cannot have pre-existed Goliath because if they had it would have been possible for them to have existed even if Goliath had never existed, and that is not possible" (1986: 317). There are numerous (metaphysically possible) obstacles to Goliath's creation, prior to its carving, so there cannot be singular propositions about Goliath until Goliath exists (has existed).

This might seem counterintuitive. To reiterate, it seems I can believe and assert things about Goliath, prior to its existence. E.g., I believe I will make Goliath, I believe Goliath will be ten-feet tall, and so on. Aren't these all things I can believe? And aren't the contents of such beliefs singular propositions that involve Goliath as a constituent? Not so. I deny that such propositions have singular content-there are no singular propositions about the merely future entity, Goliath. Indeed, I'm far from convinced that it's really so counterintuitive to hold the position that I do. To resist the challenge that this proposal is counterintuitive, let me raise two points.

\footnotetext{
18 It's plausible that presentists who accept the future is 'open' will concede that it isn't 'open' with respect to every proposition about the future. But this is consistent with my account. There are no singular propositions about merely future entities, and so no singular propositions about entities that might fail to exist (Adams 1986), but there may well be other truth-apt propositions about the future. For more on presentism and the open future, see Sect. 2.3.

19 I'm grateful to an anonymous reviewer for raising this concern.
} 
First, though without endorsing a causal theory of reference, it's worth noting that, at any moment prior to Goliath's existence, I will have had no causal interaction with Goliath. I won't have seen the statue. I won't have touched it. There are no causal chains leading from Goliath to me, such that Goliath itself can have impacted upon the way that I think about it. That being the case, it doesn't seem unreasonable to say that I might fail to entertain singular propositions that involve Goliath as a constituent.

Second, and to return to some of the original concerns: at any moment prior to carving the statue of Goliath, it remains possible that Goliath not be created. Certainly, I may form the intention to create something, but perhaps an accident will befall me on my way home tonight, such that I never sculpt again. If Goliath may never come to exist, then (we may say) the world is not yet settled as to whether or not Goliath will come to exist. There is no settled fact of the matter as to what that singular thing is. In that case, again, it doesn't seem so very counterintuitive to say that there might fail to be singular propositions about Goliath.

According to Thisness Presentism, there's at least one temporal asymmetry: there are structured singular propositions about the past, but not about the mere future. But this is no problem for the view. In fact, the above considerations can be used as part of a novel solution to a related problem facing presentism, concerning the 'asymmetry of fixity' (cf. Diekemper 2005). I address this problem in Sect. 2.3 and then return to the defence of the thisness approach to propositions in Sects. 2.4 and 2.5.

\subsection{Presentism and the 'asymmetry of fixity'}

Joseph Diekemper (2005) argues that one can only account for the 'asymmetry of fixity' (i.e. the 'open' future and the 'closed' past) via an ontological asymmetry. That is, the future is 'open' because future entities don't exist, whereas the past is 'closed' because past entities do exist. Diekemper raises this as a problem for presentism, "only present things exist," since presentists appear to accept an ontological symmetry: past and future objects don't exist.

Let's concede with Diekemper that some ontological difference between the past and future is required in order to account for the asymmetry of fixity. Even granting this concession, it's not clear that the only ontological difference sufficient is one that involves the existence of past objects. Further, there's reason to doubt Diekemper's implicit premise that presentism is unable to endorse any ontological difference between the past and the future whatsoever.

Thisness Presentism proposes that there's an ontological difference between the past and the future. That is, there are presently existing thisnesses of past entities, but no thisnesses of future entities. More precisely, although Thisness Presentism maintains that past and future objects don't exist, as a version of presentism, Thisness Presentism proposes that there are presently existing surrogates (or 'proxies') of past entities, but no such surrogates for future entities. This is a kind of ontological difference between past and future, although the presentist's ontological scruples are maintained: only present entities exist.

So, how do we account for the asymmetry of fixity? According to Thisness Presentism, the past is 'closed' in virtue of there being thisnesses of past entities, 
and the future is 'open' in virtue of there being no thisnesses of future entities. As noted, the fact that there are thisnesses of past entities implies that the existence of past entities isn't contingent, given the way things are presently, and the fact that there are no thisnesses of future entities implies that the existence of future entities is contingent. This is sufficient for presentists to account for the asymmetry of fixity.

Contrary to Diekemper's (2005) argument, presentists can account for the asymmetry of fixity without endorsing a problematic ontological asymmetry. But presentists must endorse Thisness Presentism (and the underlying ontology of thisness) in order to account for this apparent feature of reality. This is one further motivation for adopting Thisness Presentism.

\subsection{Thisnesses and presentism}

The second objection is important. According to Markosian, accepting thisnesses violates presentism, since thisnesses of past entities cannot exist without past entities. That is, Markosian insists that accepting the existence of thisnesses of past entities requires an ontological commitment to past entities. The rationale is straightforward: if Socrates's thisness is the property being (identical with) Socrates, then Socrates must exist in order to constitute that property. And, if Socrates partly constitutes being Socrates, the property can't continue to exist once Socrates has ceased to exist (Markosian 2004: 55-56).

The crucial claim here is that Socrates's thisness cannot exist without Socrates because Socrates partly constitutes the property. The quick reply to Markosian is that thisnesses aren't constituted by entities, so accepting Socrates's thisness doesn't imply the existence of Socrates. But Markosian anticipates this sort of reply and responds as follows:

I have a hard time understanding how Socrates could fail to be a constituent of Socraticity [i.e. Socrates's thisness], although, admittedly, what we say about this matter depends partly on what we say about the tricky subject of the nature of constituency. In any case ... it seems clear to me that this principle will be true: The property of being identical with $x$ exists only if $x$ itself exists. For it seems to me that, for any relation and for any object, the property of standing in that relation to that object will exist only if the object exists. (2004: 56 , fn. 15)

Markosian argues that a relation holds (and, indeed, must hold) between Socrates and his thisness. According to Markosian, the property being Socrates exists only if Socrates exists, since 'for any relation and for any object, the property of standing in that relation to that object will exist only if the object exists'. ${ }^{20}$ A complete reply must deal with this challenge.

So, let me offer the complete reply and, in doing so, reiterate certain important aspects of my account of the nature of thisnesses. According to Thisness Presentism,

\footnotetext{
${ }^{20}$ This assumes something like 'serious actualism' (see my fn. 10, in Sect. 2.1, above). I concede the plausibly of this principle and don't challenge it in my reply to Markosian.
} 
thisnesses can exist (uninstantiated) without the continued existence of the relevant entities. And, importantly, no existence-entailing relation obtains between presently existing thisnesses of past entities and the (non-existent) past entities themselves. That is, Socrates's thisness cannot exist at all without the initial existence of Socrates, but the continued existence of his thisness doesn't require that Socrates continues to exist. (Socrates's thisness depends for its existence on the initial existence of Socrates and not his continued existence.) More precisely, Socrates's thisness 'non-rigidly' ontologically depends on Socrates. So, the existence of Socrates's thisness depends on Socrates coming into being, but doesn't continue to depend on his existence; Socrates's thisness merely has depended on Socrates for its existence (and depends no longer).

\subsection{Singular propositions and thisnesses}

The third objection, adapted from Markosian, is that a thisness approach fails to provide genuine singular propositions about the past by invoking thisnesses of past entities (and not the past entities themselves) as propositional constituents (Markosian 2004: 56). Markosian urges that 'it is not at all clear that the proposition that there was a unique $\mathrm{x}$ that exemplified Socraticity and that was a philosopher is really a singular proposition about Socrates' (2004: 56).

At first pass, Markosian seems to object that $<$ There was a unique $x$ that exemplified Socrates's thisness and was a philosopher $>$ isn't a singular proposition about Socrates. This is correct. That proposition is about Socrates's thisness instead. But, as it stands, this isn't an objection to my thisness solution. According to Thisness Presentism, <Socrates was a philosopher $>$ is a structured entity, constituted by Socrates's thisness, and it's directly about Socrates (and so singular) in virtue of having his thisness as a constituent (Adams 1986: 315). Thisness Presentism doesn't replace $<$ Socrates was a philosopher $>$ with a distinct proposition, $<$ There was a unique $\mathrm{x}$ that exemplified Socrates's thisness and was a philosopher $>$, as Markosian seems to suggest.

Perhaps a more charitable reading of Markosian's objection is that $<$ Socrates was a philosopher $>$ isn't really about Socrates if it's constituted by a thisness (and not Socrates). There's a simple (yet flatfooted) reply to this objection. Recall, Markosian's preferred definition of a singular proposition about an entity, $\mathrm{x}$, is 'a proposition that involves or refers to $\mathrm{x}$ directly, perhaps by having $\mathrm{x}$ or the thisness of $x$ as a constituent' (2004: 49, fn. 4). The view of propositions provided by Thisness Presentism is perfectly consistent with this definition. <Socrates was a philosopher $>$ is a singular proposition about Socrates, which involves Socrates by having his thisness as a constituent. In slogan form: " $<$ Socrates was a philosopher $>$ is about Socrates because it has Socrates's thisness as a constituent." It's a feature of Thisness Presentism that it provides us with an analysis of when a singular proposition is about an entity. A singular proposition, $<p>$ is about an entity, $x$, if $<\mathrm{p}>$ has $\mathrm{x}$ 's thisness, T, as a constituent. The analysis might be slightly surprising to the likes of Markosian, but Markosian's surprise need not constitute a fatal objection to the current proposal. 
In reply, Markosian might insist that if $<$ Socrates was a philosopher $>$ is constituted by Socrates's thisness then it's not really about Socrates. Indeed, to further develop the objection, Markosian (2004: 56) contrasts two propositions: <Socrates was a philosopher $>$ and $<$ Plato's best teacher was a philosopher $>$. Both are about Socrates but, importantly, the latter proposition is only indirectly about him (and so isn't a singular proposition about Socrates). ${ }^{21}$ Plausibly, $<$ Plato's best teacher was a philosopher $>$ isn't directly about Socrates (and so isn't singular) because it's constituted by the property being Plato's best teacher. Here's the more developed objection. According to Markosian, if we accept $<$ Plato's best teacher was a philosopher $>$ isn't a singular proposition about Socrates, as we should, then we must also accept that $<$ Socrates was a philosopher $>$ (when constituted by Socrates's thisness) isn't a singular proposition about Socrates. Markosian reasons that the properties functioning as propositional constituents, e.g. being Plato's best teacher and being Socrates, are similar in kind. Hence, propositions constituted by them aren't genuine singular propositions. To put the challenge plainly, Markosian asks the following question: 'what is the difference between Socraticity and the property of being Plato's best teacher in virtue of which a proposition containing the former property is a singular proposition about Socrates while a proposition containing the latter property is not?' (2004: 56).

Suppose we resist the temptation to merely restate the analysis (e.g. "a singular proposition, $<\mathrm{p}>$ is about an entity, $\mathrm{x}$, if $<\mathrm{p}>$ has $\mathrm{x}$ 's thisness, $\mathrm{T}$, as a constituent"). What else can be said in reply? Here's one thought: Markosian is wrong, the two properties aren't similar in kind, and there's a difference in virtue of which a proposition containing being Socrates is a singular proposition about Socrates. The difference between the properties is that being Socrates is essential to Socrates whereas being Plato's best teacher is only accidental to him. In fact, being Socrates is an 'individual essence' of Socrates. ${ }^{22}$ That Socrates happened to be Plato's best teacher is contingent, whereas Socrates being Socrates is absolutely essential. The fact $<$ Socrates was a philosopher $>$ is constituted by Socrates's thisness allows us to say that $<$ Socrates was a philosopher $>$ is directly about Socrates (and so singular). The fact $<$ Plato's best teacher was a philosopher $>$ is constituted by an accidental property of Socrates allows us to say that $<$ Plato's best teacher was a philosopher $>$ is only indirectly about Socrates (and so not singular). So, regardless of Markosian's resistance to the analysis, there's good independent reason to think a proposition constituted by x's thisness is a singular proposition about $\mathrm{x}$ (whereas a proposition constituted by another property of $\mathrm{x}$ isn't a singular proposition about $\mathrm{x}) .^{23}$

\footnotetext{
21 There's a link between propositions being 'directly about' entities and being singular propositions. Paraphrasing Alvin Plantinga, " $<$ Socrates was a philosopher $>$ involves Socrates in a more direct and intimate way than does $<$ Plato's best teacher was a philosopher $>$. In fact, $<$ Plato's best teacher was a philosopher $>$ is about Socrates accidentally (or 'indirectly'), in virtue of the fact Socrates happened to be Plato's best teacher; $<$ Socrates was a philosopher $>$ is directly (and not accidentally) about Socrates" (Plantinga 1983: 3).

22 Socrates's thisness is an individual essence because it's an essential property that's only ever instantiated by Socrates.

23 Markosian (2004: 56) offers a fourth and final objection that I don't consider in any detail here. The objection is an apparent dilemma arising from two previous objections (Sects. 2.4, 2.5). According to Markosian, either singular propositions about the past aren't genuine, and the problem facing presentism remains unresolved; or, the singular propositions about the past are genuine, but this implies an
} 
One might object that it's simply unclear how a proposition can be about something that doesn't exist. How can $<$ Socrates was a philosopher $>$ be about Socrates, either directly or indirectly, when Socrates doesn't exist at all? ${ }^{24}$ To reply, I think that this potential unclarity emerges from making one key (false) assumption about the nature of 'aboutness'. Specifically, one assumes that 'aboutness' is a relation that links entities, e.g. a proposition ( $<$ Socrates was a philosopher $>$ ) and an individual (Socrates). To be clear, I think there's no relation of 'aboutness' at work here. (At least, there's no metaphysically heavyweight relation that entails the existence of both relata, i.e. proposition and individual.) In this respect, I align with Trenton Merricks (2007) who makes the point quite neatly as follows: 'I do not deny, however, that in a different and more familiar sense of 'about', that Queen Anne has been dead some years is 'about something' - obviously, it is 'about Queen Anne'. But this no more implies that Queen Anne exists than a ghost story's being 'about ghosts' implies that ghosts exist' (2007: 137 , fn. 17). I think that $<$ Socrates was a philosopher $>$ is 'about Socrates' in a way that doesn't demand the existence of Socrates, and this is underpinned by the fact that the proposition is partly constituted by Socrates's thisness. Indeed, it's this notion of aboutness that's at issue in the above analysis: a singular proposition, $<\mathrm{p}>$ is about an entity, $\mathrm{x}$, if $<\mathrm{p}>$ has $\mathrm{x}$ 's thisness, $\mathrm{T}$, as a constituent.

\subsection{Summary}

A thisness solution to the problem facing presentism concerning the existence of structured singular propositions about the past is plausible and successful. An account of singular propositions, given in terms of presently existing thisnesses of past entities, is prima facie acceptable to presentists. Further, Markosian (2004), a leading opponent of a thisness approach, provides no definitive objections to undermine the solution outlined. Presentists should opt for an approach to singular propositions involving thisnesses and accept Thisness Presentism.

\section{Presentism and the 'myth of passage'}

Lisa Leininger (2015) argues presentists can't account for temporal passage because of an incompatibility between two claims: (i) only the present exists, and (ii) what's present changes. In particular, Leininger argues presentists aren't justified in positing presently existing surrogates of past entities to resolve the incompatibility,

\footnotetext{
Footnote 23 continued

objectionable connection between thisnesses and the past. However, since I've shown the previous objections fail, so the dilemma can be dissolved quickly. (The first horn: " $<$ Socrates was wise $>$ isn't directly about Socrates, if it's constituted by Socrates's thisness." The second horn: "the only way for Socrates's thisness to generate 'direct aboutness' between singular proposition and Socrates is by having Socrates as a constituent.") According to Thisness Presentism, $<$ Socrates was wise $>$ is directly about Socrates if $<$ Socrates was wise $>$ has Socrates's thisness as a constituent. And this, in turn, doesn't imply that Socrates exists to constitute Socrates's thisness. Thisnesses are unstructured entities and Socrates's thisness non-rigidly ontologically depends on the initial existence of Socrates.

24 I'm grateful to an anonymous reviewer for pressing me on this point.
} 
i.e. using present resources to account for the fact that what's present changes. In this section, I introduce the problem in a little more detail (Sect. 3.1) and rehearse Leininger's challenge against positing presently existing surrogates of past entities (Sect. 3.2). I reply and present Thisness Presentism as a version of presentism that involves surrogates but resists Leininger's challenge (Sect. 3.3).

\subsection{The problem of passage}

Can a presentist, who believes "only present things exist," account for temporal passage? According to Leininger (2015), presentists cannot, since two central elements of presentism are incompatible. These two elements are: "only the present exists: past and future moments don't exist" (Present Thesis), and "what's present changes: there's a difference in what exists from moment to moment" (Change Thesis).

Leininger's (2015) argument has three steps. First, the passage of time-that what's future approaches the present, becoming less future, and that what's past recedes, becoming more past-requires temporal change. Second, temporal change, i.e. that what's present changes (from moment to moment), requires a difference in the character of each successive present moment. And, third, establishing a difference between two (successive) moments requires that both moments exist (2015: 730). This generates the advertised incompatibility between the Present Thesis and the Change Thesis: temporal change requires the existence of more than one moment, but only one moment (the present moment) exists.

Leininger anticipates (and rejects) one line of response on behalf of the presentist. That is: '...to appeal to presently existing surrogates to accommodate the former privileged nature of a past moment, and thereby to establish the succession of creation and annihilation needed for temporal change in the presentist picture' (2015: 731). The basic idea is as follows. Presentists can postulate presently existing resources to serve as proxies for past moments in order to account for temporal change. Presentists can thus compare the present moment with a proxy past moment in order to establish that what's present has changed (2015: 731-732). But Leininger argues that presentists aren't justified in appealing to presently existing surrogates in this way. According to Leininger, an account of the reality of temporal change must preclude the possibility of a 'one-instant world' (i.e. a world with no events preceding or succeeding the present instant), but an appeal to present surrogates doesn't rule out the possibility of the one-instant world. Presentists can't account for temporal change by positing surrogates if positing surrogates doesn't rule out this possibility (2015: 732).

In what follows, I sketch Leininger's challenge that the presentist's account of temporal change doesn't rule out the possibility of a one-instant world in a little more detail (Sect. 3.2). Then, I present Thisness Presentism and show how this view can account for temporal change in a way that rules out the possibility of a oneinstant world (and thus resolves Leininger's problem facing presentism) (Sect. 3.3).

\subsection{Against surrogates}

Consider a one-instant world OIW, which is different from the actual world @ since there are no past or future events at OIW. There's no temporal change at OIW, but 
there's change at @. To account for temporal change, presentists must develop a view that precludes the possibility of the one-instant world. As Leininger writes: 'that in virtue of which there is temporal change must preclude the possibility of a one-instant world' (2015: 732). If presentists use presently existing surrogates (of past things) in order to account for temporal change, it must be in virtue of the existence of such surrogates that OIW is shown to be impossible. This is the criterion of success for the presentist's account of temporal change.

Leininger proposes the 'One Instant Test' to evaluate whether an account of temporal change precludes the possibility of the one-instant world, OIW. The test (or 'OIT') is framed as a question:

Suppose that God creates only this one instant, exactly as it is NOW. Is he able to create-in this one instant- the relevant ingredients by which the presentist establishes temporal change? (2015: 732)

To pass the test, the answer to the OIT must be 'No'. The presentist's account of temporal change must guarantee that the world persists; if the world persists then it's not a one-instant world, and the reality of temporal change requires this fact (2015: 732-733). Put another way, if God can create one (temporally isolated) instant of the world, which includes all the materials used by presentists to account for temporal change, then such presently existing materials lack an appropriate connection to the past moments (and things, more generally) for which they are supposed proxies. This isn't enough to establish that what's present really changes. Failing the OIT implies failing to account for temporal change.

Leininger's argument (against surrogates) is elegant and compelling. Presentists can't account for genuine temporal change by positing presently existing surrogates (of past things) because the existence of such surrogates doesn't guarantee that the world persists (i.e. the appeal to surrogates is compatible with the possibility of the one-instant world). Leininger considers three main presentist accounts of surrogates and shows how each fails the OIT. To illustrate, I rehearse Leininger's case against one such presentist account, due to John Bigelow (1996), in what remains of Sect. 3.2.

Bigelow (1996) proposes that all truths about the past, i.e. truths about what was the case, are made true by the world presently instantiating primitive tensed properties. $^{25}$ For example, $<$ Caesar existed $>$ is made true by the world now instantiating having contained Caesar. The proposed 'truth-makers' in this case are tensed facts (or states of affairs): presently existing facts about how the world was. Leaving aside the issue of truth-makers, the question here is: can the existence of tensed facts establish that another moment exists and so preclude the possibility of the one-instant world? Put another way, can this view account for temporal change? Leininger thinks not.

According to Leininger's view fails the OIT (2015: 733). Can God create only this one instant, exactly as it is now, and in that instant also create all of the relevant tensed facts? Leininger suggests that the presentist must say 'Yes' (and fail the

25 See also, e.g., Chisholm (1990a, b), Keller (2004: 94-96), Crisp (2007), and McDaniel (2014), inter alia. Bigelow cites Lucretius's De Rerum Natura as the origin of this sort of view (and introduces the label 'Lucretianism'). 
OIT). Bigelow's presentist cannot, for instance, stipulate that tensed facts-present instantiations of primitive past-tensed properties-are caused by past events themselves, and so couldn't exist at a one-instant world. Why not? Well, as Leininger (2015: 733) writes: 'If the events in the past caused the past-tensed properties to exist in the present, then this causal relation necessitates the existence of the relata-both the past-tensed properties and the existence of the past'. This would be a bad result for presentism. Further, according to Leininger, Bigelow's presentist can't maintain the causal story, without the troublesome existenceentailing necessitation, because 'there needs to be some kind of connection between the formerly existing past and past-tensed properties to pass the OIT' (2015: 733). In sum, Bigelow's tensed properties (and facts) cannot be used as surrogates to account for temporal change because such properties (and facts) are independent of the existence of the past.

I concede that Bigelow's presentist (as presented above) can't account for temporal change. And I'm also sympathetic to further remarks against the other presentist accounts of surrogates. But Leininger doesn't establish definitively that there's nothing a presentist can say about their proposed surrogates of past entities to avoid the worry. In fact, I think Thisness Presentism can solve the problem. (As it happens, Leininger (2015: 733, fn. 15) anticipates and rejects something like Thisness Presentism as a solution. But the rejection is too hasty.) Next, in Sect. 3.3, I explain how Thisness Presentism solves the problem and reply directly to Leininger.

\subsection{Thisness Presentism and passage}

Let's begin with a quick recap. According to Thisness Presentism, x's thisness (being $x$ ) comes into being with $\mathrm{x}$, is uniquely instantiated by $\mathrm{x}$ throughout $\mathrm{x}$ 's existence, and continues to exist uninstantiated when $\mathrm{x}$ has ceased to exist. Hence, there are thisnesses of present entities, e.g. Colbert's thisness (being Colbert), and uninstantiated thisnesses of past entities, e.g. Caesar's thisness (being Caesar).

To paraphrase Leininger, "thisnesses of past entities (i.e. moments) are apt to play the role of presently existing surrogates, used to accommodate the former privileged nature of a past moment, thereby establishing the succession of creation and annihilation needed for temporal change in the presentist picture. That is, thisnesses can serve as proxies for past moments in order to account for temporal change; the present moment can be compared with the uninstantiated thisness of a past moment in order to establish that what's present has changed" (2015: 731-732). But does this view pass the OIT? That is, can God create only this one instant, exactly as it is now, and in that instant also create all of the relevant uninstantiated thisnesses of past entities? (Leininger thinks so, but I disagree.)

Leininger briefly argues that this sort of view can't account for temporal change for the same sort of reasons that undermine Bigelow's presentist (as above):

[Thisness Presentism] ... encounters a difficulty similar to the difficulty that Bigelow's account faces. Specifically, these haecceities get created by the same events that bring about the existence of their individuals. Thus, there 
needs to be a causal connection between past events and the presently existing haecceities. (2015: 733, fn. 15)

Leininger is correct that there must be a connection (at some time) between a thisness ( $\mathrm{T}$ ) and object ( $\mathrm{x}$ ), since $\mathrm{x}$ comes into being with $\mathrm{T}$ and $\mathrm{T}$ couldn't exist without the initial existence of $\mathrm{x}$. Indeed, this is why the existence of $\mathrm{T}$ can be used to determine that $\mathrm{x}$ did exist. But Leininger's claim that 'there needs to be a causal connection' between $\mathrm{x}$ and $\mathrm{T}$ is false. The connection between object $\mathrm{x}$ and its thisness $\mathrm{T}$ isn't the troublesome existence-entailing relation of causal necessitation. And the relevant connection between $\mathrm{x}$ and $\mathrm{T}$ doesn't have to persist beyond the initial existence of $\mathrm{x}$. As such, Leininger is wrong to dismiss this sort of view so quickly. (More cautiously: so long as the nature of thisnesses, and the connection between object and thisness, can be adequately developed, Leininger's argument hasn't definitively undermined Thisness Presentism.)

Thisness Presentism passes the OIT: God cannot create only this instant, exactly as it is now, and also create all uninstantiated thisnesses of past entities. Consider the thisness of an individual (rather than a moment, for simplicity), e.g. Caesar's thisness, the property being Caesar. Caesar's thisness exists now, without Caesar, but couldn't exist before Caesar existed. According to Thisness Presentism, Caesar's thisness 'non-rigidly' ontologically depends on Caesar ${ }^{26}$; Caesar's thisness couldn't exist without the initial existence of Caesar. However, this dependence doesn't imply that Caesar's thisness ceases to exist once Caesar ceases to exist. The initial existence of Caesar is sufficient for the existence of Caesar's thisness; the loss of Caesar doesn't necessitate the loss of Caesar's thisness.

So, recall Leininger's 'One Instant Test' (OIT) to evaluate whether an account of temporal change precludes the possibility of the one-instant world. Can God create only this one instant, exactly as it is now, and in that instant also create all of the relevant uninstantiated thisnesses of past entities? To pass the test, the answer to this question must be 'No'. According to Thisness Presentism, the answer is 'No'. God cannot create uninstantiated thisnesses of past entities at a one-instant world. Necessarily, for any $x, x$ 's thisness $T$ exists only if $x$ has existed; the fact that the connection between $\mathrm{x}$ and $\mathrm{T}$ doesn't always obtain, doesn't undermine the fact that $\mathrm{T}$ cannot exist without the initial existence of $\mathrm{x}$. (Quite generally, given the account of the nature of thisnesses put forward in Sect. 1, there cannot be any thisnesses of entities that haven't yet existed.)

The Thisness Presentist's account of temporal change thus precludes the possibility of a one-instant world. If there are uninstantiated thisnesses of past entities, then there must have been past entities. This undermines Leininger's (2015) argument that presentists aren't justified in appealing to presently existing surrogates (in order to establish some difference between successive moments). Thus, presentists have a way to resolve the incompatibility between the Present

\footnotetext{
${ }^{26}$ Recall the definition of (asymmetric, temporal) non-rigid ontological dependence (from Sect. 1.4): $\mathrm{x}$ non-rigidly ontologically depends on $y==_{\mathrm{df}}$; (1) necessarily, $\mathrm{x}$ exists only if y has existed; and, (2) it's not the case that, necessarily, $y$ exists only if $x$ has existed. This is the sense in which $x$ 's thisness, T, ontologically depends on $\mathrm{x}$.
} 
Thesis ('only the present exists') and the Change Thesis ('what's present changes'): the present moment can be compared to a proxy past moment, i.e. an uninstantiated thisness of a past moment, in order to establish that what's present has changed. This provides a further reason for presentists to endorse Thisness Presentism.

\section{Conclusion}

In this paper, I've presented my preferred version of presentism ('Thisness Presentism') and shown how it can be used to solve at least three problems facing standard iterations of presentism. Since it solves these problems, Thisness Presentism is preferable to other versions of presentism. This is a good positive reason in favour of it and the underlying thisness ontology.

Acknowledgments I'm very grateful to Jonathan Tallant and an anonymous referee for this journal for comments on a previous draft. Special thanks to Adam Tiller, who commented on my paper 'Thisness Presentism and Singular Propositions' at the Philosophy of Time Society meeting at the 2014 Eastern APA, for very helpful feedback concerning the overall project.

Open Access This article is distributed under the terms of the Creative Commons Attribution 4.0 International License (http://creativecommons.org/licenses/by/4.0/), which permits unrestricted use, distribution, and reproduction in any medium, provided you give appropriate credit to the original author(s) and the source, provide a link to the Creative Commons license, and indicate if changes were made.

\section{References}

Adams, R. M. (1974). Theories of actuality. Noûs, 8(3), 211-231.

Adams, R. M. (1979). Primitive thisness and primitive identity. The Journal of Philosophy, 76(1), 5-26.

Adams, R. M. (1981). Actualism and thisness. Synthese, 49(1), 3-41.

Adams, R. M. (1986). Time and thisness. Midwest Studies in Philosophy, 11, 315-329.

Bigelow, J. (1996). Presentism and properties. Philosophical Perspectives, 10, 35-52.

Bourne, C. (2011). Fatalism and the future. In C. Callender (Ed.), The Oxford handbook of philosophy of time (pp 41-67). Oxford: Oxford University Press.

Braun, D. (1993). Empty names. Noûs, 27(4), 449-469.

Cameron, R. (2011). Truthmaking for presentists. In K. Bennett \& D. W. Zimmerman (Eds.), Oxford studies in metaphysics (vol. 6, pp. 55-100). Oxford: Oxford University Press.

Cartwright, R. (1997). On singular propositions. Canadian Journal of Philosophy, 27(Suppl), 67-83.

Chisholm, R. (1990a). Events without times: an essay in ontology. Noûs, 24(3), 413-427.

Chisholm, R. (1990b). Referring to things that no longer exist. Philosophical Perspectives, 4, 545-556.

Clark, K. J., \& Rea, M. C. (Eds.). (2012). Reason, metaphysics, and mind. Oxford: Oxford University Press.

Crisp, T. (2004). On presentism and triviality \& Reply to Ludlow. In D. Zimmerman (Ed.), Oxford studies in metaphysics (Vol. 1, pp. 15-20 \& 37-46). Oxford: Oxford University Press.

Crisp, T. (2007). Presentism and the grounding objection. Noûs, 41(1), 90-109.

Diekemper, J. (2005). Presentism and ontological symmetry. Australasian Journal of Philosophy, 83(2), $223-240$.

Diekemper, J. (2009). Thisness and events. The Journal of Philosophy, 106(5), 255-276.

Diekemper, J. (2014). The existence of the past. Synthese, 191(6), 1085-1104.

Diekemper, J. (2015). The ontology of thisness. Philosophy and Phenomenological Research, 90(1), 49-71.

Fine, K. (1994). Essence and modality. Philosophical Perspectives, 8, 1-16. 
Fitch, G. W. (1994). Singular propositions in time. Philosophical Studies, 73(2-3), 181-187.

Fitch, G. W. (1996). In defense of Aristotelian actualism. Philosophical Perspectives, 10, 53-71.

Fitch, G. W., \& Nelson, M. (2014). Singular propositions. In E.N. Zalta (Ed.), The Stanford Encyclopedia of Philosophy (Fall 2014). http://plato.stanford.edu/archives/fall2014/entries/propositions-singular/.

Kaplan, D. (1989). Demonstratives \& Afterthoughts. In J. Almog, J. Perry, \& H. Wettstein (Eds.), Themes from Kaplan (pp. 481-563 \& 565-614). Oxford: Oxford University Press.

Keller, S. (2004). Presentism and truthmaking. In D. Zimmerman (Ed.), Oxford studies in metaphysics (Vol. 1, pp. 83-104). Oxford: Oxford University Press.

King, J. (2007). The nature and structure of content. Oxford: Oxford University Press.

King, J. (2014). Structured propositions. In E.N. Zalta (Ed.), The Stanford Encyclopedia of Philosophy (Spring 2014). http://plato.stanford.edu/archives/spr2014/entries/propositions-structured/.

Leininger, L. (2015). Presentism and the myth of passage. Australasian Journal of Philosophy, 93(4), 724-739.

Lewis, D. (1979). Counterfactual dependence and time's arrow. Nô̂s, 13(4), 455-476.

Lewis, D. (1986). On the plurality of worlds. Oxford: Blackwell.

Lowe, E. J. (2006). The four-category ontology. Oxford: Oxford University Press.

Lowe, E. J. (2010). Ontological dependence. In E. N. Zalta (Ed.), The Stanford Encyclopedia of Philosophy (Spring 2010). http://plato.stanford.edu/archives/spr2010/entries/dependenceontological/.

Lycan, W. G. (1994). Modality and meaning. London: Kluwer.

Markosian, N. (2004). A defense of presentism. In D. Zimmerman (Ed.), Oxford studies in metaphysics (Vol. 1, pp. 47-82). Oxford: Oxford University Press.

McDaniel, B. (2014). A defense of lucretianism. American Philosophical Quarterly, 51(4), 373-385.

McKinnon, N. (2003). Presentism and consciousness. Australasian Journal of Philosophy, 81(3), $305-323$.

Menzel, C. (2015). Actualism. In E. N. Zalta (Ed.), The Stanford Encyclopedia of Philosophy (Spring 2015). http://plato.stanford.edu/archives/spr2015/entries/actualism/.

Merricks, T. (2007). Truth and ontology. Oxford: Oxford University Press.

Merricks, T. (2012). Singular propositions. In K. J. Clark \& M. C. Rea (Eds.), Reason, metaphysics, and mind (pp. 61-81). Oxford: Oxford University Press.

Merricks, T. (2015). Propositions. Oxford: Oxford University Press.

Plantinga, A. (1974). The nature of necessity. Oxford: Oxford University Press.

Plantinga, A. (1976). Actualism and possible worlds. Theoria, 42(1-3), 139-160.

Plantinga, A. (1979). De essentia. Grazer Philosophische Studien, 7(8), 101-121.

Plantinga, A. (1983). On existentialism. Philosophical Studies, 44(1), 1-20.

Putnam, H. (1967). Time and physical geometry. The Journal of Philosophy, 64(8), 240-247.

Rosenkrantz, G. (1993). Haecceity: An ontological essay. London: Kluwer.

Salmon, N. (1986). Frege's puzzle. Cambridge: MIT Press.

Salmon, N. (2007). About aboutness. European Journal of Analytic, Philosophy, 3(2), 59-76.

Sider, T. (2001). Four-dimensionalism. Oxford: Oxford University Press.

Sider, T. (2006). Quantifiers and temporal ontology. Mind, 115, 75-97.

Soames, S. (1987). Direct reference, propositional attitudes, and semantic content. Philosophical Topics, $15,47-87$.

Speaks, J. (2012). On possibly nonexistent propositions. Philosophy and Phenomenological Research, $85(3), 528-562$.

Tallant, J. (2014). Defining existence presentism. Erkenntnis, 79(3), 479-501.

Van Inwagen, P. (1986). Two concepts of possible worlds. Midwest Studies in Philosophy, 11, 185-213.

Williamson, T. (2002). Necessary existents. In A. O'Hear (Ed.), Logic, thought and language (pp. 233-251). Cambridge: Cambridge University Press.

Zimmerman, D. (2008). The privileged present: Defending an "A-theory" of time'. In T. Sider, J. Hawthorne, \& D. Zimmerman (Eds.), Contemporary debates in metaphysics (pp. 211-225). Oxford: Blackwell. 